
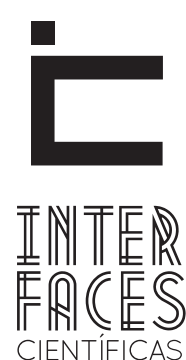

HUMANAS E SOCIAIS

\title{
REFLEXÕES SOBRE A INFLUÊNCIA DO MERCADO EDITORIAL EM A MÁQUINA, DE ADRIANA FALCÃO
}

\section{RESUMO}

0 presente artigo tem por objetivo proceder a uma reflexão sobre a relação estabelecida entre a prosa brasileira contemporânea e o mercado editorial. Tendo como via de acesso o romance A Máquina (1999), da escritora Adriana Falcão. Esta abordagem parte do princípio de que a leitura crítica do objeto artístico na atualidade exige a adoção de novos parâmetros e o mercado pode ser um dos indicadores, dada a sua participação no presente contexto de produção estética. Para tanto, serão acionados estudos desenvolvidos por Beatriz Rezende, Karl Erik Schollhammer e Silviano Santiago.

\section{PALAVRAS-CHAVE}

Romance Contemporâneo. Mercado Editorial. Ponto de Vista Periférico. Nordestina. 


\section{ABSTRACT}

This article aims to make a reflection on the relation between contemporary Brazilian prose and publishing. With the access road to the romance "A Maquina" (1999), by Adriana Falcão. This approach assumes that the critical reading of the art object today requires the adoption of new standards and the market may be one of the indicators, given its participation in the present context of aesthetic production.

\section{RESUMEN}

Este artículo tiene como objetivo hacer una reflexión sobre la relación entre la prosa brasileña contemporánea y el mercado editorial. Teniendo como el camino de acceso la novela A Máquina (1999), de la escritora Adriana Falcão. Este enfoque asume que la lectura crítica del objeto artístico actual requiere la adopción de nuevas normas y el mercado puede ser uno de los indicadores, dada su participación en el contexto ac-
To this end, studies will be triggered developed by Beatriz Rezende, Karl Erik Schollhammer and Silviano Santiago.

\section{KEYWORDS}

Contemporary Romance. Publishing Market. Point of Peripheral View. Northeastern.

tual de la producción estética. Por lo tanto, serán buscados los estudios desarrollados por Beatriz Rezende, Karl Erik Schollhammer y Silviano Santiago.

\section{PALABRAS CLAVE}

Novela Contemporánea. Mercado Editorial. Punto de Vista Periférico. Nordestina. 


\section{INTRODUÇÃO}

Partindo do princípio de que os artefatos artísticos guardam estreita relação com o tempo e o espaço onde estão inseridos percebe-se que o seu entendimento depende da compreensão das relações, que estabelece com o seu entorno temporal, cultural, histórico e social. Assim, para entender a deliberação dos elementos que encerra o todo temático de um objeto artístico é necessário interrogá-lo no cotejo com o contexto em que se insere. Pois, o artefato artístico carrega em seu cerne, não apenas, as marcas do espaço onde subsiste, mas também contribui para a sua construção.

Nesse sentido, este artigo parte do entendimento de que o estudo crítico sobre um objeto artístico produzido na atualidade deva, também, levar em conta a sua relação com as contendas do mercado. Uma vez que, os sistemas de produção mercadológicos interferem na produção dos bens culturais, do mesmo modo com que interferem na produção de quaisquer mercadorias.

Em se tratando da literatura, de modo mais específico, a possibilidade de considerar o mercado como prisma de leitura é ofertada pela necessidade de adoção de novos parâmetros críticos, sobretudo, quando se considera a produção mais recente. Pois, as múltiplas faces do romanceiro atual se revelam na forma, no conteúdo, nos canais utilizados pelos autores para tornar púbica a sua construção e no modo com que o livro é comercializado.

Desse modo, ao ensejar a leitura crítica do romance A Máquina (1999), o que se pretende é, não apenas, considerar determinados aspectos da obra com relação ao mercado, mas também colocar em movimento novas perspectivas teóricas e metodológicas para o estudo crítico. Afinal os novos rumos do estudo literário não podem se ater a uma teoria que se restrinja a explicar a natureza da literatura ou discorrer acerca dos métodos para o seu estudo.

Destarte, a obra será relacionada com o mercado a partir de um ponto especifico: o seu foco narrativo. Ainda faz parte dos propósitos deste texto levantar al- gumas nuances sobre a forma com a qual a escritora Adriana Falcão transita pelos canais midiáticos para divulgar o seu trabalho.

\section{PONTO DE VISTA NARRATIVO E O MERCADO}

0 romance A Máquina, que norteia a execução deste trabalho, foi publicado em 1999, portanto é um romance contemporâneo. Em se tratando da produção ficcional brasileira, a contemporaneidade, na concepção de muitos estudiosos, é marcada pela heterogeneidade tanto temática quanto formal. 0 professor, crítico e poeta Ítalo Mariconi, que no ano 2000 organizou e publicou a coletânea intitulada: Os Cem Melhores Contos Brasileiros do Século, destaca que variados estilos coabitam na esfera da produção literária brasileira no presente.

No entanto, apesar de a heterogeneidade ser um traço marcante da prosa produzida no atual cenário brasileiro, uma ampla gama de estudiosos argumenta que em meio à multiplicidade ficcional, alguns elementos destacam-se como recorrentes, dentre os quais a adoção do ponto de vista periférico no flagrante aos acontecimentos da trama. O romance A Máquina, que figura como tema deste trabalho é ambientando em Nordestina, uma pequena cidade do interior do Brasil, invisível no mapa do mundo e distante de outras localidades, como se observa em:

Nordestina era uma cidade deste tamanhinho assim da qual se dizia: eita lugarzinho sem futuro. [...] Para chegar a Nordestina tinha que se andar bem muito. É claro que ninguém fazia isso. 0 que é que a pessoa ia fazer num lugar que não tinha nada pra fazer? (FALCÃO, 2005, p. 12).

Nada podia estar mais afastado um negócio do outro do que nordestina do mundo [...] Juntar os dois era serviço mais difícil do que dissolver a terra inteira no mar, misturando bem misturado, não importando nem o tamanho da colher de pau, nem a habilidade da criatura que se prestasse a executar tarefa tão ingrata. (FALCÃO, 2005, p. 43-44).

Partindo dos fragmentos anteriores é possível per- 
ceber que a cidade é caracterizada pela pequenez. Ela é dita pelos seus moradores, como uma cidade sem futuro e sem atrativos. A ficção enfoca a Nordestina dos anos 2000, um lugar decadente, que diariamente vai diminuindo o número de habitantes, por se recusarem a viver: "num lugar que não tem nada para fazer" (FALCÃO, 2005, p. 12).

Era tanta gente indo embora que o povo até se acostumou com os vazios que ficavam e iam tomando conta da cidade, apagando cheiros, transformando em memória frases, olhares, gestos, e a cara daqueles que não tinham retrato. (FALCÃO, $2005^{3}$, p. 14)

Assim, é possível perceber que a narrativa aclimata-se num lugarejo de fisionomia acanhada que vive o conflito do seu esmaecimento, dada à quantidade de moradores que se deslocavam para outras cidades. Os poucos habitantes que ainda estavam na cidade, passavam os dias refletindo sobre os conterrâneos que haviam evadido:

\footnotetext{
- O povo vai embora porque aqui não tem recursos.

- E por que não mandam recursos pra cá?

- Mandar recursos pra cá pra que se o povo está todo indo embora?

- Pro povo ficar aqui.

- Mas se aqui não tem recursos!

- Se hoje é segunda, amanha é terça.

- Não foi numa terça que dona Ernestina foi embora? (FALCÃO, 2005, p. 20-21).
}

Observa-se então que a autora focaliza o esmorecimento da pequena cidade esquecida nos cafundós de um país de metrópoles vultosas. Neste sentido, a atitude da romancista revela uma tendência constante entre os escritores do século XX: destacar a realidade sob a ótica periférica. Habitualmente tal perspectiva refere-se às zonas marginais das grandes metrópoles. No caso de A Máquina, o periférico alude ao realce dado a uma cidade distante do grande centro urbano, ou seja, uma zona socialmente desvalorizada. Assim, torna-se perceptível que a escolha do ponto de vista convoca o romance citado a partilhar de uma caracte-

3. Embora o romance tenha sido publicado em 1999, a edição contemplada pelo estudo presente é a de 2005. rística contumaz na prosa brasileira contemporânea.

Em 2008, a crítica Beatriz Rezende publicou um livro intitulado: Contemporâneos: expressões da literatura brasileira do século XXI. Nele a autora traça um panorama sobre a prosa brasileira produzida entre o final do século XX e o início do século XXI e destaca que a produção atual é marcada pela inserção de diferentes mecanismos ficcionais dentre os quais tem importante relevo os espaços de onde ecoam os discursos narrativos. A partir disso, ela afirma: "que novas vozes surgem de espaços que até recentemente estavam afastados do universo literário" (REZENDE, 2008, p. 93). Para Rezende a sonoridade produzida em diferentes localidades ecoa como um movimento de reação contra a globalização da cultura.

Já para o professor e teórico Karl Erik Schollhammer, a persistência de uma produção ficcional dedicada ao retrato de zonas socialmente desvalorizadas, é antes de tudo um reflexo do apelo mercadológico:

[...] essa e a exata expressão de um conflito que não tem solução, já que a incorporação mercadológica dessa produção marginal, [...] parece ser inevitável e acaba impondo uma condição com a qual as próprias iniciativas periféricas tem de lidar e aceitar, uma vez que isso significa sua possibilidade de sobrevivência num contexto cultural altamente perverso. (SCHOLLHAMMER, 2009, p. 100).

A perspectiva de Schollhammer oportuniza a ponderação de que embora o ímpeto de relacionar a arte, de modo geral, e a literatura, de modo especifico, com as demandas da atualidade, seja um dos elementos que melhor expliquem a presente diversidade literária. Não se pode negligenciar a percepção de que as mais variadas formas de arte, dentre elas a literatura, subsiste em sua relação com o mercado. Pois no cenário atual - múltiplo e capitalista - os ditames de mercado interferem nas contendas da sua produção.

Por esta razão, já não é mais possível entender a produção literária sem relacioná-la com o mercado editorial. 0 escritor e crítico Silviano Santiago observa que uma das significativas mudanças que marcam 
a prosa literária pós-64 diz respeito à ligação entre 0 escritor e o mercado:

\begin{abstract}
Tudo indica que no estágio atual do tardio processo de modernização por que passa a sociedade brasileira, o romancista jovem poderá abdicar do trabalho literário como bico, passatempo noturno ou atividades de fins de semana, para se consagrar à sua profissão em regime de full time, como um bom escritor europeu, americano ou, mais recentemente, hispano-americano. A editora por sua vez, assume uma forma de empresa capitalista, pois já diz abertamente que visa ao lucro como qualquer outra indústria do país. (SANTIAGO, 2002, p. 28 - Grifos do autor).
\end{abstract}

Ao se pensar a editora como uma indústria que visa o lucro e o escritor como um funcionário desta indústria, há de se considerar, também, as exigências do mercado, afinal o leitor/consumidor entra em cena como um elemento fundamental da engrenagem produtiva do cenário mercadológico.

Assim, transformado em mercadoria dentro da sociedade de consumo, o livro passa a ter um temível (porque imprevisível) e subordinável (porque manipulável) árbitro: o público. É ele que, segundo a empresa, atesta anônima, economicamente e autoritariamente sobre o "valor" da obra, digo mercadoria, como qualquer teste Ibope ou índice de vendagem. Bons escritores são os que vendem, diz a voz do lucro empresarial (SANTIGO, 2002, p. 28-29).

Desse modo, a confecção de um livro além de atender aos objetivos artísticos do autor precisa estar em sintonia com os anseios do público consumidor. $\mathrm{E}$, ao que parece produtor e consumidor conseguiram alinhar os seus anseios literários, pois segundo a Câmara Brasileira do Livro, o cenário é ascendente. 0 crescimento nominal do setor editorial no Brasil em 2013 foi de $7,52 \%$.

Para Karine Pansa, empresária do ramo e atual presidente da Câmara Brasileira do Livro (CBL), o crescimento do mercado e a utilização do Vale Cultura, do governo federal, permitem refletir sobre o postulado de que o brasileiro não lê. Segundo Pansa:

Estamos assistindo a uma paulatina mudança his- tórica. São várias as causas dessa transformação, dentre elas a democracia, a liberdade de imprensa e expressão. Os primeiros resultados do Vale Cultura, relativos ao movimento acumulado de janeiro a junho de 2014, questionam o dogma de que o brasileiro não lê: $88,01 \%$ dos $\mathrm{R} \$ 13,65$ milhões consumidos no período pelos portadores dos 215.249 cartões emitidos referem-se à compra de livros, jornais e revistas. (PANSA, 2014, [on-line]).

0 aumento das vendas enuncia que possivelmente o número de novos leitores também esteja em crescimento. Como anteriormente discutido, a prosa brasileira de hoje, habitualmente, tem sido marcada pelo trato de zonas socialmente desvalorizadas, a partir do ponto de vista marginal. Isso permite pensar que esta abordagem agrada o leitor, mas que também atrai novos leitores.

$E$, se formos mais além e relacionarmos o uso do Vale Cultura, destinado aos cidadãos economicamente desfavorecidos, na aquisição dos livros e a emergente elaboração de textos que contemplem as zonas periféricas, faz-se possível imaginar um elo entre as partes. Assim, estes números favorecem a suposição de que o retrato das zonas periféricas estimula a aparição de novos leitores e pode ser que estes iniciantes consumidores literários estejam localizados em camadas populacionais que anteriormente não tinham interesse por este tipo de produto.

Assim, percebe-se que a onda editorial, que favorece a aparição de personagens e histórias antes esquecidas pela ficção nacional, pode estar associada ao compromisso social dos escritores e formadores de opinião. Ou podem atender ao anseio de retratar uma realidade antes negligenciada. $\mathrm{Ou}$, ainda, possa ser fruto da necessidade urgente de denúncia das dificuldades da vida nas periferias. Mas, sem excluir, nenhuma das possibilidades anteriores, pode ter estreita relação com o mercado. Diante disso, pode-se levantar a hipótese de que os detentores do Vale Cultura, possivelmente, representem um nicho para um mercado em franco desbravamento. 


\section{AUTOR E OS MEANDROS DO MERCADO EDITORIAL}

Beatriz Rezende acena, ainda, para o fato de que em função do barateamento dos equipamentos para produção, tornou-se mais fácil e mais barato publicar, pois novas editoras entraram no mercado e a comercialização do livro ganhou novos contornos:

[...] é fácil constatar que se publica muito, que novos escritores e editoras surgem todos os dias, e que consome-se e comenta-se literatura. Nas grandes cidades, novas livrarias partilham o mesmo espaço com outras formas de lazer tornando o convívio com o livro mais sedutor. Surgiram nos últimos anos novos prêmios literários com valores bem mais altos que no passado. (REZENDE, 2008 p. 16 - Grifos da autora).

Nesse sentido, observa-se que a figura do autor ganha certo relevo e, muitas vezes, ante a espetacularização da sua imagem de celebridade Cult, ele é instigado a agradar o público para permanecer em evidência. Um bom exemplo desta aparição com ares de fama é a Festa Literária Internacional de Paraty (Flip). A pequena cidade litorânea no interior do Rio de Janeiro promove anualmente o evento, onde escritor e obra são as grandes estrelas. Assim, importantes nomes internacionais apresentam e debatem as suas criações. Ao mesmo tempo em que os brasileiros conhecidos ou promissores divulgam as suas publicações.

Sobre a Flip, que em julho de 2015 terá a sua décima terceira edição, Beatriz Rezende (2008, p. 16) assinala:

A repetição da Festa Literária Internacional de Paraty vem conseguindo apresentar escritores brasileiros ao lado dos nomes mais importantes do cenário internacional em um evento que se tornou, em aparente contradição, ao mesmo tempo Cult e popular.

Adriana Falcão, autora do romance A Máquina, participou de algumas edições da Festa Literária de Paraty. Em uma delas, a escritora foi a convidada de uma oficina promovida pelo encarte Folhinha do jornal Folha de São Paulo. A culminância da oficina intitulada Entrevistando, se deu quando quatorze adolescentes de Paraty, participantes do evento entrevistaram a autora e, como resposta para uma das perguntas que the foram feitas, Adriana respondeu: “É engraçado, em Paraty, a gente vira 'popstar'. Na vida normal, isso não acontece com escritores, mas sim com atores, com cantores. Mas é muito bom. Aqui na Flip estou me sentido uma Madonna" (MANCINI e VEIGA, 2010 [on-line]).

A colocação da romancista exprime em certa medida, os artifícios utilizados pela indústria editorial para promover os escritores e consequentemente fomentar a venda de seus livros. Segundo Schollhammer (2009, p. 17), a Festa Literária de Paraty, abriu caminho para uma série de eventos similares, espalhados por várias regiões do país e, este feito é justificado em função de ser um "modelo comercialmente bem-sucedido".

As declarações da carioca representam um recorte exemplar da ação do mercado editorial para alavancar a figura do ficcionista, buscando aproximar as suas experiências das experiências do leitor. Este, então, passa a identificar-se com aquele, isso gera a impressão de estar, o próprio leitor, impresso no livro. Nutrido pelo desejo de reconhecer-se no que está escrito, o leitor/consumidor adquire o exemplar. Isso demonstra que altos índices de vendas não são um significado direto da qualidade do texto. De modo similar, uma vendagem pequena, não é um referente negativo da obra, pois, na atualidade, a relação que se estabelece entre a obra e o leitor é mediada pelo mercado. Para Schollhammer (2009, p. 21), as estatísticas de venda e os prêmios literários "representam mecanismos eficientes de canonização e marketing" dos quais se valem o mercado editorial.

A Máquina marca a estreia de Falcão como romancista. A sua publicação ficou a cargo da editora Objetiva. Para além de quaisquer considerações que se faça sobre a qualidade da obra ter sido publicada por uma prestigiada editora, é um feito que nem todos os autores iniciantes conseguem alcançar. Todavia, na ocasião do lançamento a autora era roteirista da Rede 
Globo, a maior emissora televisiva do Brasil e este fato foi largamente enfatizado pela mídia, tanto para apresentar a obra como a autora.

Na contracapa da primeira edição do romance, por exemplo, Falcão é assim descrita: "Roteirista da TV Globo, escreveu para as séries Comédia da vida privada e Brasil legal. Atualmente trabalha para o programa Mulher. A Máquina é seu primeiro romance". Outra referência que não escapou do olhar midiático foi o seu casamento com João Falcão, festejado roteirista da mesma emissora e diretor teatral de grande importância no cenário da época.

Sobre isto, o texto da referida contracapa (1999) é construído da seguinte maneira:

\begin{abstract}
Adriana Falcão nasceu no Rio de Janeiro, em 1960, mas passou boa parte da sua vida em Recife. 0 sotaque e a vocação para o humor não negam seu lado pernambucano. Foi lá que ela se formou em arquitetura, profissão que nunca exerceu, casou-se com João Falcão e teve três filhas, Tatiana, Clarice e Isabel.
\end{abstract}

Uma rápida reflexão sobre os meandros do mercado faz crer que o comércio do livro deva ser um negócio lucrativo. Acena também com a possibilidade de haver ampla concorrência, dada a quantidade de escritores e que provavelmente o mercado arbitra mais do que se supõe na produção estética do autor. Mais uma vez é Schollhammer, que ilumina a nossa perspectiva, pois segundo ele:

[...] a impressão de falta de homogeneidade entre os estreantes desta década da "geração 00 ", talvez seja uma consequência da abertura do mercado editorial, que acabou por criar uma relva densa de muitos novos títulos com poucos nomes de destaque e liderança. 0 número de escritores estreantes, a partir da década de 1990, é muito maior do que na década de 1970 e não para de crescer. Um magro volume de contos às vezes basta para converter 0 aspirante em escritor de qualidade, até o contrário ser comprovado. (SCHOLLHAMMER, 2009, p. 19).

A partir deste ponto de vista, vamos incluir Falcão nesta "relva densa" como uma estreante que tentava em 1999, ter um nome de destaque dentro desta grandiosa safra de escritores insurgentes. Assim, num ambiente de escrita heterogênea, com certo predomínio do trato das grandes metrópoles e com poucos representantes do Nordeste, a investida no emblema de uma cidadezinha decadente chamada Nordestina poderia soar oportuna. Nesse sentido, a autora foi apresentada ao público a partir da ênfase da sua relação com Pernambuco. Como se verifica na apresentação da primeira edição de $A$ Máquina, feita por Luis Fernando Veríssimo e também, no comentário de Mario Prata, na contracapa da segunda edição:

\begin{abstract}
A prosa de Adriana tem sortilégio. A gente se encanta com ela no sentido de se deliciar, mas também no sentido de cobra hipnotizada. De chegar ao fim e não saber bem o que aconteceu. Olha aí, outro talento surpreendente. De onde sai essa gente? Eu sei, eu sei. De Pernambuco. (VERÍSSIMO, 1999).

Essa menina mostra o Nordeste para o mundo, gargalhando de amor. Pintando a sua pequena aldeia como diria Tolstoi, tornou-se universal. (PRATA, 2005).
\end{abstract}

Colocações desta natureza fazem crer que exista a intenção de levar o leitor a buscar a identidade de nordestina de Falcão - embora ela seja carioca - impressa nas páginas do romance. A partir disso, pode se estar autorizado a pensar que o enfoque no drama de uma Nordestina abatida remeta o leitor a uma série de escritos especialmente os da década de trinta, ambientados no Nordeste brasileiro. 0 que favorece uma leitura palatável, sem questionamentos e de venda fácil. Afinal, o leitor inicia a leitura com um cabedal prévio de informações que lhes foram impostas ao longo do tempo.

\section{CONSIDERAÇÕES FINAIS}

O estudo que ora se apresenta objetivou proceder à leitura crítica do romance A Máquina (1999) da escritora Adriana Falcão, sob a ótica do mercado, tendo como ponto de partida o seu foco narrativo. Embora uma colocação de caráter absolutamente conclusivo não seja a pretensão deste estudo e nem tenha cabi- 
mento, em um momento marcado pela transitoriedade, é possível perceber que os ditames mercadológicos se instauram na produção literária recorrente de modo contundente.

A adoção do ponto de vista periférico é um viés que caracteriza o romanceiro contemporâneo, porém se habitualmente a história é contada a partir da periferia de uma grande metrópole, Falcão elege um lugarejo invisível no mapa do mundo, para aclimatar à narrativa. Para alguns teóricos visitados aqui, a constância de tal ocorrência representa menos uma reação contra a indústria cultural que uma estratégia da própria indústria para despertar o interesse de pessoas que ao se identificar com os personagens, possivelmente se tornariam novos leitores ou consumidores. Assim, o atual estudo permite conjecturar sobre a influência do mercado na adoção do ambiente e do ponto de vista marginal que entrecorta a trama.

\section{REFERÊNCIAS}

CULLER, Jonathan. Teoria literária uma introdução. Tradução de Sandra Vasconcelos. São Paulo: Beca,1999.

FALCÃO, Adriana. A máquina. Rio de Janeiro: Objetiva, [1999] 2005.

MANCINI, Gabriela; VEIGA, Patricia Trudes da. Adriana Falcão diz se sentir "uma Madonna na Flip”. Folha de São Paulo, 07/08/2010. Disponível em: <http://www1.folha.uol.com.br/ folhinha/2010/08/779111-adriana-falcao-diz-sesentir-uma-madonna-na-flip.shtml>. Acesso em: 24 mai. 2015

MARICONI, Ítalo. A poesia brasileira do século XX. Rio de Janeiro: Objetiva, 2002.
MARICONI, Ítalo (Org.). Os cem melhores poemas

brasileiros do século. Rio de Janeiro: Objetiva, 2001.

PANSA, Karine. Quem disse que brasileiro não lê?

Câmara brasileira do livro, 15 de julho de 2014. Disponível em: <http://www.cbl.org.br/telas/opiniao/ opiniao-detalhes.aspx?id=2067>. Acesso em: $17 \mathrm{abr}$. 2015

PEREIRA, Helena Bonito. Leitura: Teoria \& Prática. Associação de Leitura do Brasil. - ano 1, 1982 Campinas, SP: Global, 2013.

PINTO, Manuel da Costa. Literatura brasileira hoje. São Paulo: Publifolha, 2004.

REZENDE, Beatriz. Contemporâneos: expressões da literatura brasileira no século XXI. Rio de Janeiro: Casa da Palavra: Biblioteca Nacional, 2008.

SANTIAGO, Silviano. Democratização no Brasil -- 1979-1981 (Cultura versus Arte). In: ANTENELO, Raul (Org.). Declínio da arte: ascensão da cultura. Florianópolis:

ABRALIC: Letras contemporâneas, 1998.

SANTIAGO, Silviano. A vida como literatura: 0 amanuense Belmiro. Belo Horizonte: UFMG: 2006.

SANTIAGO, Silviano. Nas malhas da letra: ensaio. Rio de Janeiro Rocco, 2002.

SCHOLLHAMMER, Karl Erik. Ficção brasileira contemporânea. Rio de Janeiro: Civilização Brasileira, 2009. 
Recebido em: 26 de Julho de 2015

Avaliado em: 31 de Agosto de 2015

Aceito em: 31 de Agosto de 2015
1. Mestre em Crítica Cultural pelo Programa de Pós-Graduação em Crítica Cultural da Universidade do Estado da Bahia

(UNEB);Especialista em Comunicação em Língua Portuguesa

(UNIVERSO);Graduada em Letras, com habilitação em Língua

Portuguesa e Literaturas (UCSAL). E-mail: monicagrisi@gmail.com 
